Supporting information for the manuscript

\title{
Tuning the Strength of Molecular Bonds in Oxygenates via Surface-Assisted Intermolecular Interactions: Atomistic Insights
}

Carsten Schröder, Marvin C. Schmidt, Christopher Witt, Smadar Attia, Jann Weber, AnnKatrin Baumann, Bernd Hartke and Swetlana Schauermann*

Corresponding author: schauermann@pctc.uni-kiel.de

Institut für Physikalische Chemie, Christian-Albrechts-Universität zu Kiel

Max-Eyth-Str. 2, 24118 Kiel, Germany

\section{TABLE S1: Assignment of vibrational modes of ethyl pyruvate}

The assignment of the vibrational bands was performed based on the theoretically computed spectrum as well as experimentally measured spectra of isotopically labelled ${ }^{13} \mathrm{C}$-EP. The references cited in the table demonstrate that the assignment performed in this study is in agreement with the previously published one.

\begin{tabular}{|c|c|c|c|c|c|c|}
\hline \multicolumn{5}{|c|}{ Frequency $\mathrm{cm}^{-1}$} & \multirow[t]{2}{*}{ Assignment } & \multirow[t]{2}{*}{ Ref. } \\
\hline${ }^{12} \mathrm{C}$ & & ${ }^{13} \mathrm{C}$ & & B3LYP & & \\
\hline $\begin{array}{l}\text { Sub- } \\
\text { monolayer } \\
{[95 \mathrm{~K}]}\end{array}$ & $\begin{array}{l}\text { Multilayer } \\
{[95 \mathrm{~K}]}\end{array}$ & $\begin{array}{l}\text { Sub- } \\
\text { monolayer } \\
{[95 \mathrm{~K}]}\end{array}$ & $\begin{array}{l}\text { Multilayer } \\
{[95 \mathrm{~K}]}\end{array}$ & $\begin{array}{l}\text { aug-cc- } \\
\text { pVTZ scaled } \\
(\mathrm{f}=0.9858)\end{array}$ & & \\
\hline $\begin{array}{l}2988 \\
2972\end{array}$ & $\begin{array}{l}2987 \\
2981\end{array}$ & $\begin{array}{l}2989 \\
2974\end{array}$ & $\begin{array}{l}2986 \\
2978\end{array}$ & $3104-2996$ & $v(\mathrm{C}-\mathrm{H})_{\mathrm{x}}$ & 8 \\
\hline \multirow[t]{3}{*}{1530} & 1753 & 1529 & 1750 & 1739 & $v(\mathrm{C}=\mathrm{O})_{\text {ester }}$ & 9 \\
\hline & 1741 & & 1701 & 1775 & $v(\mathrm{C}=\mathrm{O})_{\text {acetyl }}$ & 10 \\
\hline & 1476 & & 1474 & 1477 & $\delta_{\mathrm{as}}\left(\mathbf{C H}_{2}-\mathrm{CH}_{3}\right)$ & 8,11 \\
\hline 1465 & 1465 & 1460 & 1460 & 1464 & $\delta_{\mathrm{s}}\left(\mathbf{C H}_{\mathbf{2}}-\mathrm{CH}_{3}\right)$ & 11 \\
\hline 1444 & 1447 & 1442 & 1445 & 1440 & $\delta_{\mathrm{as}}\left(\mathrm{CH}_{2}-\mathbf{C H}_{\mathbf{3}}\right)$ & $8,10-13$ \\
\hline \multirow[t]{2}{*}{1428} & 1424 & 1428 & 1426 & 1436 & $\delta_{\mathrm{as}}\left(\mathrm{CH}_{3}\right)$ & $10-11$ \\
\hline & 1360 & & 1360 & 1373 & $\delta_{\mathrm{s}}\left(\mathrm{CH}_{3}\right)$ & $8,10,13-14$ \\
\hline \multirow[t]{3}{*}{$\begin{array}{l}1296 \\
1268\end{array}$} & 1313 & $\begin{array}{l}1296 \\
1268\end{array}$ & 1306 & 1290 & $\begin{array}{l}v(\mathrm{C}-\mathrm{O})_{\text {ester }, 1} \\
v(\mathrm{C}-\mathrm{O})_{\text {ester }, 2}\end{array}$ & 10,13 \\
\hline & 1162 & & 1143 & 1150 & $v_{\text {mixed }}(C-C-C)$ & \\
\hline & 1116 & & 1116 & 1118 & $\rho\left(\mathrm{O}-\mathrm{C}_{2} \mathrm{H}_{5}\right)$ & 10 \\
\hline 1020 & 1028 & 1018 & 1027 & 1026 & $\rho\left(\mathrm{C}_{2} \mathrm{H}_{5}\right) / v(\mathrm{C}-\mathrm{C})$ & 8 \\
\hline \multirow[t]{2}{*}{1006} & 1010 & 1002 & 1010 & 1024 & $v(C-C)$ & 10,13 \\
\hline & 975 & & 975 & 965 & $\rho\left(\mathrm{CH}_{3}\right)$ & 12 \\
\hline
\end{tabular}




\section{Graphical illustration of the calculated mixed mode vibration at $1150 \mathrm{~cm}^{-1}$ of gaseous ethyl pyruvate.}

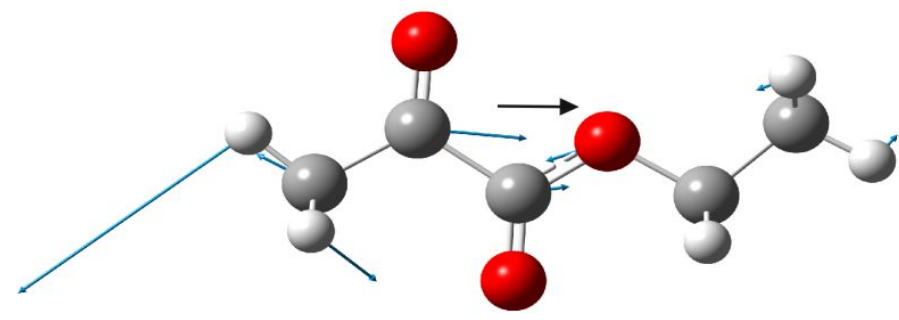

Figure S1. Graphical illustration of the calculated mixed mode vibration at $1150 \mathrm{~cm}^{-1}$ of gaseous ethyl pyruvate. Blue arrows show the displacement vectors of the atoms participating in the vibration. The resulting dynamic dipole moment vector lies in the $\mathrm{C}-\mathrm{C}-\mathrm{C}-\mathrm{O}$ plane is shown as a black arrow.

\section{Full experimental details for Figures 2-5.}

Figure 2. IRAS spectra of EP adsorbed on $\mathrm{Pt}(111)$ at $100 \mathrm{~K}$ obtained after dosing of EP at a flux of $7.2 \cdot 10^{12}$ molecules $\cdot \mathrm{s}^{-1} \cdot \mathrm{cm}^{-2}$. The spectra were obtained for (a) increasing EP exposure: (1) $1.4 \cdot 10^{13}$, (3) $4.3 \cdot 10^{13}$, (3) $7.2 \cdot 10^{13}$, (4) $1.0 \cdot 10^{14}$, (5) $1.1 \cdot 10^{14}$, (6) $1.3 \cdot 10^{14}$ molecules $\cdot \mathrm{cm}^{-2}$; and (b) during in-situ $\mathrm{H}_{2}$ exposure at a constant coverage of EP. The initial coverage of EP (spectrum 1) amounts to $7.2 \cdot 10^{13}$ molecules $\cdot \mathrm{cm}^{-2}$. The spectra (2)-(5) were acquired after $\mathrm{H}_{2}$ exposures indicated on the right side of $(b)$.

Figure 3. (a) STM image of EP adsorbed on pristine $\operatorname{Pt}(111)$ (exposure at $135 \mathrm{~K}$, acquisition temperature $118 \mathrm{~K}, 611 \mathrm{mV}, 0.267 \mathrm{nA}, 52.2 \times 52.2 \mathrm{~nm}^{2}$ ). (b) Close-up images of different oligomers divided in $\mathrm{S}_{(\mathrm{STM})}$ (dimers D1, D2 and D3) and $\mathrm{S} 2_{(\mathrm{STM})}$ (dimer D4, trimers $\mathrm{T} 1$ and $\mathrm{T} 2$, tetramers $\mathrm{O} 1$ and $\mathrm{O} 2$ ) species. Note that the dimer D4 was observed only on H-covered $\operatorname{Pt}(111)$ surface.

Figure 4. (a) STM images $\left(37.3 \times 37.3 \mathrm{~nm}^{2}\right)$ of EP adsorbed on pristine $\mathrm{Pt}(111)$ at different coverages. The images were obtained at $105-120 \mathrm{~K}$ for the following surface coverages of EP: (I) $1.8 \cdot 10^{12}$, (II) $10.5 \cdot 10^{12}$, (III) $13.5 \cdot 10^{12}$, (IV) $70.7 \cdot 10^{12}$ molecules $\cdot \mathrm{cm}^{-2}$. Imaging conditions: $130-800 \mathrm{mV}$, typical tunnelling currents of $0.1-0.5 \mathrm{nA}$. (b) Absolute number of two types of surface species $\mathrm{S} 1_{(\mathrm{STM})}$ and $\mathrm{S} 2_{(\mathrm{STM})}$ shown for different EP surface coverages. (c) Relative abundance of two types of surface species $\mathrm{S} 1_{(\mathrm{STM})}$ and $\mathrm{S} 2_{(\mathrm{STM})}$ shown for different $\mathrm{EP}$ surface coverages. In both cases, statistical evaluation was done for an area larger than shown in (a) $\left(52.2 \times 52.2 \mathrm{~nm}^{2}\right)$

Figure 5 (a) STM images $\left(32.9 \times 32.9 \mathrm{~nm}^{2}\right)$ of EP adsorbed on Pt(111) obtained after different $\mathrm{H}_{2}$ exposures indicated on the horizontal axis. The images were obtained at $110 \mathrm{~K}$ after the exposure to EP followed by in situ $\mathrm{H}_{2}$ exposure in the STM chamber. Imaging conditions: 127$144 \mathrm{mV}$, typical tunnelling currents of $0.2-0.3 \mathrm{nA}$. (b) Relative abundance of two types of surface species $\mathrm{S} 1_{(\mathrm{STM})}$ and $\mathrm{S} 2_{(\mathrm{STM})}$ shown for different $\mathrm{H}_{2}$ exposures. Statistical evaluation was done for an area larger than shown in (a) $\left(52.2 \times 52.2 \mathrm{~nm}^{2}\right)$ 


\section{REFERENCES}

1. Attia, S.; Spadafora, E. J.; Hartmann, J.; Freund, H.-J.; Schauermann, S., Molecular Beam/Infrared Reflection-Absorption Spectroscopy Apparatus for Probing Heterogeneously Catalyzed Reactions on Functionalized and Nanostructured Model Surfaces. Rev. Sci. Instrum. 2019, 90, 053903.

2. Giannozzi, P., et al., Advanced Capabilities for Materials Modelling with Quantum Espresso. J. Phys.: Condens. Matter 2017, 29, 465901.

3. Giannozzi, P., et al., Quantum Espresso: A Modular and Open-Source Software Project for Quantum Simulations of Materials. J. Phys.: Condens. Matter 2009, 21, 395502.

4. $\quad$ Perdew, J. P.; Burke, K.; Ernzerhof, M., Generalized Gradient Approximation Made Simple. Phys. Rev. Lett. 1996, 77, 3865-3868.

5. Dal Corso, A., Pseudopotentials Periodic Table: From H to Pu. Comput. Mater. Sci. 2014, 95, 337-350.

6. Tersoff, J.; Hamann, D. R., Theory of the Scanning Tunneling Microscope. Phys. Rev. B 1985, 31, 805-813.

7. $\quad$ Frisch, M. J., et al. Gaussian 16 Rev. C.01, Wallingford, CT, 2016.

8. Maes, I. I.; Herrebout, W. A.; van der Veken, B. J., Vibrational Conformational Analysis of Ethyl Formate. J. Ram. Spec. 1994, 25, 679-691.

9. Demers-Carpentier, V.; Rasmussen, A. M. H.; Goubert, G.; Ferrighi, L.; Dong, Y.; Lemay, J.-C.; Masini, F.; Zeng, Y.; Hammer, B.; McBreen, P. H., Stereodirection of an A-Ketoester at Sub-Molecular Sites on Chirally Modified Pt(111): Heterogeneous Asymmetric Catalysis. J. Amer. Chem. Soc. 2013, 135, 9999-10002.

10. Burkholder, L.; Tysoe, W. T., Structure and Reaction Pathways of Methyl Pyruvate on Pd(111). J. Phys. Chem. C 2009, 113, 15298-15306.

11. Nolin, B.; Jones, R. N., The Infrared Absorption Spectra of Deuterated Esters: I. Methyl Acetate. Can. J. Chem. 1956, 34, 1382-1391.

12. George, W. O.; Houston, T. E.; Harris, W. C., Vibrational Spectra and Structure of EstersI. Infrared and Raman Spectra of $\mathrm{CH}_{3} \mathrm{COOCH}_{3}, \mathrm{CH}_{3} \mathrm{COOCD}_{3}, \mathrm{CD}_{3} \mathrm{COOCH}_{3}$ and $\mathrm{CD}_{3} \mathrm{COOCD}_{3}$. Spectrochim. Acta A: Mol. Spec. 1974, 30, 1035-1057.

13. Castonguay, M.; Roy, J. R.; Rochefort, A.; McBreen, P. H., Orientation and Conformation of Methyl Pyruvate on Ni(111). J. Amer. Chem. Soc. 2000, 122, 518-524.

14. Burkholder, L.; Tysoe, W. T., Structure and Reaction Pathways of Methyl Lactate on Pd(111). Surf. Sc. 2009, 603, 2714-2720.

15. Attia, S.; Schauermann, S., Coverage-Dependent Adsorption Geometry of Acetophenone on Pt(111). J. Phys. Chem. C 2020, 124, 557-566.

16. Attia, S.; Schmidt, M.-C.; Schröder, C.; Pessier, P.; Schauermann, S., Surface-Driven KetoEnol Tautomerization: Atomistic Insights into Enol Formation and Stabilization Mechanisms. Angew. Chem. Int. Edit. 2018, 57, 16659-16664. 